\title{
Ultrasonographic measurement of cross-sectional area of the median and ulnar nerves in healthy Japanese children
}

\author{
Takamichi SUGIMOTO $^{1,2)}$, Kazuhide OCHI ${ }^{3)}$, Takeshi KITAMURA ${ }^{1)}$, Kazuki MUGURUMA ${ }^{1,3)}$, \\ Tatsuo KOHRIYAMA ${ }^{4)}$, Masayasu MATSUMOTO ${ }^{3)}$, Hirofumi MARUYAMA ${ }^{3)}$ \\ 1) Department of Neurology, Chugoku Rosai Hospital \\ 2) Department of Neurology, Hiroshima City Hiroshima Citizens Hospital \\ 3) Department of Clinical Neuroscience and Therapeutics, Hiroshima University Graduate School of Biomedical and Health Sciences \\ 4) Department of Neurology, Brain Attack Center, Ota Memorial Hospital
}

\section{超音波検査による健常小児の正中・尺骨神経断面積に関する検討}

\author{
杉本 太路 ${ }^{1,2)}$, 越智 一秀 ${ }^{3)}$, 北村 健 $^{1)}$, 六車 一樹 ${ }^{1,3)}$, 郡山 達男 ${ }^{4)}$, 松本 昌泰 ${ }^{3)}$, 丸山 博文 ${ }^{3)}$ \\ 1) 中国労災病院神経内科 \\ 2) 広島市立広島市民病院脳神経内科 \\ 3) 広島大学大学院脳神経内科学 \\ 4) 脳神経センター大田記念病院脳神経内科
}

\begin{abstract}
Ultrasonography is a painless and rapid method, which is attractive for testing in children. The objective of this study was to try to measure a cross-sectional area (CSA) at predetermined sites along the median and ulnar nerves in children by ultrasonography. The CSAs measured by ultrasonography were determined bilaterally at the mid-humerus of median nerve (MedArm) and the arterial split of ulnar nerve (UlnProx) in 20 healthy Japanese children from 1 to 6 years old. Participants were 10 boys and 10 girls, $4.0 \pm 1.8$ years of age. The maximum value of CSA at the MedArm was $5 \mathrm{~mm}^{2}$ up to 3 years old and $7 \mathrm{~mm}^{2}$ from 4 to 6 years old. The maximum value of CSA at the UlnProx was $3 \mathrm{~mm}^{2}$ up to 3 years old and $4 \mathrm{~mm}^{2}$ from 4 to 6 years old. We identified the possibility of the ultrasonographic measurement of nerve sizes in children who were younger than those of the previous studies for children.
\end{abstract}

Keywords: ultrasonography, median nerve, ulnar nerve, children

(Received June 5, 2018; Accepted September 27, 2018)

\section{Introduction}

Ultrasonographic nerve enlargement along the peripheral nerves has been recognized as a differential finding between peripheral neuropathies, such as demyelinating Charcot-Marie-Tooth disease (CMT), chronic inflammatory demyelinating polyneuropathy (CIDP), GuillainBarré syndrome (GBS), multifocal motor neuropathy, vasculitic neuropathy and leprosy in adults ${ }^{1-3)}$. We proposed that ultrasonographic evaluation of cross-sectional area (CSA) at some sites along the bilateral median and ulnar nerves can differentiate demyelinating CMT from CIDP $^{4}$. And we have reported ultrasonographic peripheral refer- ence nerve size at multiple sites along median and ulnar nerves in healthy Japanese adults ${ }^{1)}$.

Ultrasonographic peripheral nerve enlargement has been reported in children with demyelinating CMT of an average of 11.4 years old from Australia ${ }^{5}$. Zaidman et al. described nerve enlargement in children with CIDP and $\mathrm{GBS}^{(6)}$. In Japan, no studies exist for ultrasonographic evaluation of nerve sizes in children. The measurement of CSAs of the nerves in children may be useful to identify such diseases.

In this study, we tried to measure the CSA at predetermined proposed sites along the median and ulnar nerves in children by ultrasonography. 
Left MedArm

Example 1)

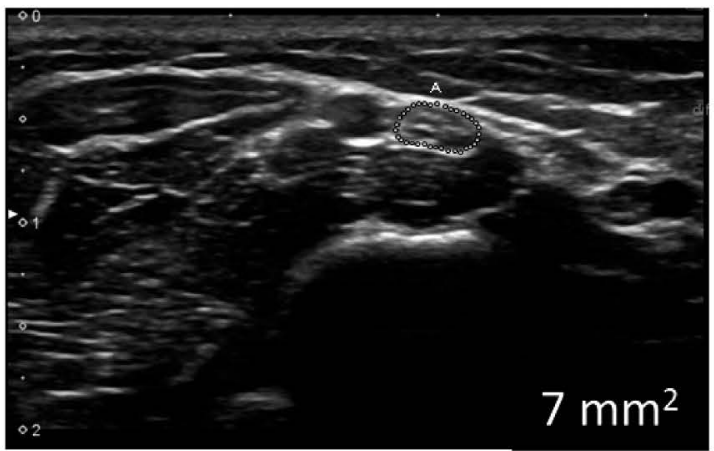

Example 2)

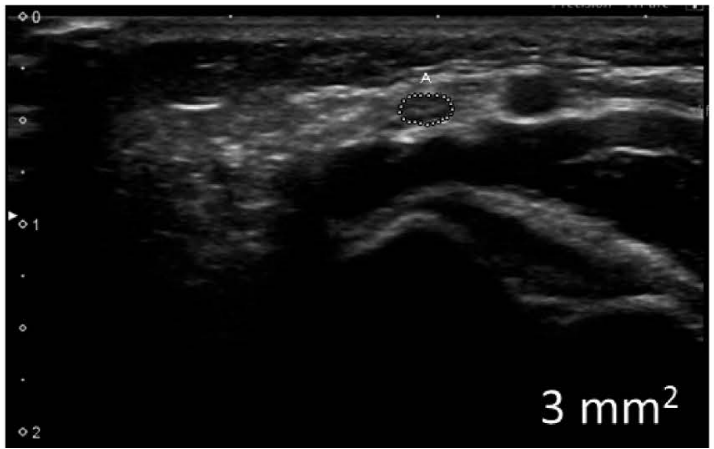

Left UlnProx
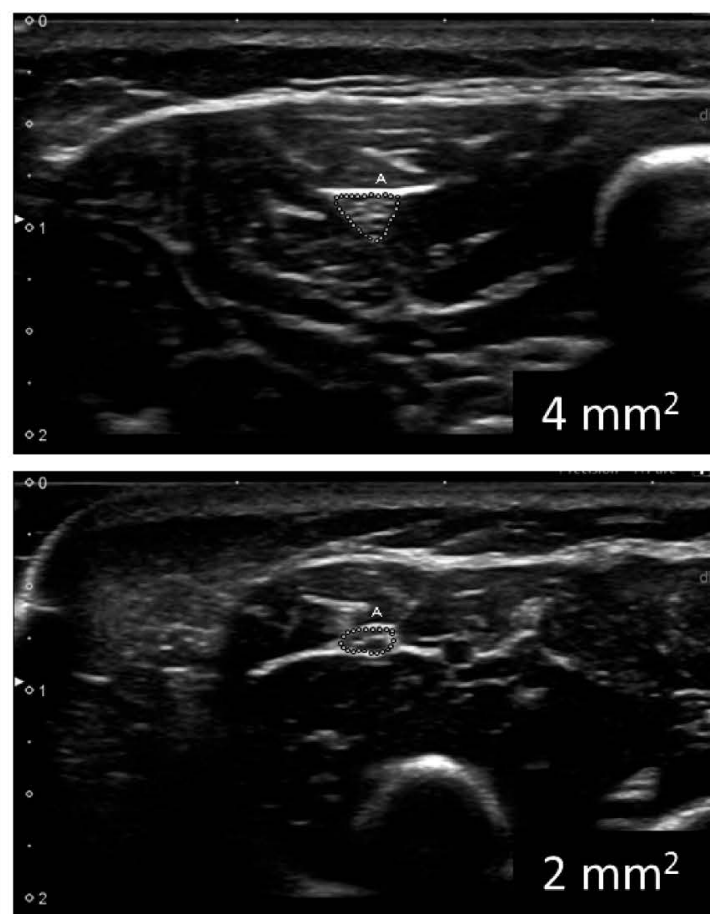

Fig.1 Image examples of the evaluated sites along the median and ulnar nerves

Ultrasonographic CSA images at the left MedArm and left UlnProx are presented in example 1) a 4.6-year-old healthy girl, $99.7 \mathrm{~cm}$ in height, $14.5 \mathrm{~kg}$ in weight and $10.7 \mathrm{~cm}$ in wrist circumference on the left side, and 2) a 1.7-year-old healthy girl, $81.8 \mathrm{~cm}$ in height, $10.5 \mathrm{~kg}$ in weight and $10.6 \mathrm{~cm}$ in wrist circumference on the left side.

This study was approved by the ethics committee of Chugoku Rosai Hospital.

\section{Methods}

\section{Participants}

Twenty healthy Japanese children from 1 to 6 years of age who had no family history of neurological disorders were enrolled. All the participants provided written informed consent from their parents and had undergone medical regular checkups in Japan. We compared the heights and weights of the participants with cross-sectional growth chart for boys and girls (0-6 years) in the 2000 National Growth Survey on Preschool Children \& School Health Statistics Research from The Japanese Society for Pediatric Endocrinology ${ }^{7}$.

\section{Ultrasonographic measurement of nerve cross- sectional area}

Ultrasound examinations were performed using an Xario 200 TUS-X200 imaging system (Toshiba, Tokyo, Japan) with a $7-18 \mathrm{MHz}$ linear array transducer. All of the participants were examined in the supine position or in their parent's arms with the examined arm supinated and abducted at body level. The CSA was measured bilaterally along the median and ulnar nerves by tracing the nerve just inside the hyperechoic rim (corresponding to the epineurium) as previously reported $^{4)}$. Proposed sites that were differentiated from demyelinating CMT and CIDP in adults as previously reported $^{1)}$ were selected as the evaluation sites. Each site along the median and ulnar nerves was evaluated bilaterally: the mid-humerus along the median nerve (MedArm: one-third to midpoint of the distance between the elbow crease and the axilla along the median nerve) and the arterial split along the ulnar nerve (UlnProx: where the nerve separates from the ulnar artery at approximately two-thirds of the distance from the distal wrist crease to the elbow crease) (Fig.1). There was a total of four evaluation sites in each participant. The minimal CSA values were $1 \mathrm{~mm}^{2}$. CSA was evaluated by a single ultrasonographer (T.S.) who was well-trained for the evaluation of CSA at MedArm and UlnProx in adults.

\section{Physical characteristics}

We included boys and girls and recorded their age, height, weight, body mass index (BMI) and wrist circumference as physical characteristics of each participant on the basis of previous studies ${ }^{4-6}$. We inquired the age of when the children began to crawl and walk from their parents. The wrist circumference was measured at the distal wrist crease with a precision of $1 \mathrm{~mm}$. 


\section{Statistical analysis}

Statistical analyses were performed using IBM SPSS Statistics version 19 (Chicago, IL, USA). The Mann-Whitney $U$ test or paired $t$-test was performed for intergroup comparison. Coefficients of determination were calculated as the square of the Pearson correlation coefficient and were used to verify the associations between each parameter (age, height or weight). One investigator (T.S.) obtained all ultrasonographic images from the participants.

\section{Results}

The baseline characteristics of the participants are presented in Table 1. Ten boys and ten girls participated in this study. There were no significant differences in the height, weight and wrist circumference between the boys and girls. Coefficients of determination between age and height, age and weight, height and weight were 0.94, 0.73, and 0.82 , respectively ( $p<0.001$ for each). Heights and weights were within mean \pm 2 standard deviation in nineteen participants. Height was slightly lower than average minus 2 standard deviation in one participant, and the weight was within average plus one standard deviation. Evaluations of CSAs for the predetermined sites were possible in all participants. The CSAs at the MedArm sites were different between boys and girls (Fig.2a; $p=0.026$ ), and the CSAs at UlnProx sites were not different between boys and girls (Fig.2b; $p=0.471$ ). The CSAs at the UlnProx were smaller than those of the MedArm (Fig.2c; $p<$ 0.001). The mean CSA was $4.5 \pm 1.2 \mathrm{~mm}^{2}$ (mean \pm standard deviation) at the MedArm and $2.8 \pm 0.7 \mathrm{~mm}^{2}$ at the UlnProx. No laterality was detected for the mean CSA at the MedArm $\left(4.30 \pm 1.0 \mathrm{~mm}^{2}\right.$ on the right side, $4.60 \pm$ $1.4 \mathrm{~mm}^{2}$ on the left side) or at the UlnProx $(2.75 \pm$ $0.7 \mathrm{~mm}^{2}$ on the right side, $2.75 \pm 0.8 \mathrm{~mm}^{2}$ on the left side).

The CSAs along the peripheral nerves and parameters (age, height and weight) are presented in Fig.3. The maximum value of CSA at the MedArm was $5 \mathrm{~mm}^{2}$ up to 3 years old and $7 \mathrm{~mm}^{2}$ from 4 to 6 years old. The maximum value of CSA at the UlnProx was $3 \mathrm{~mm}^{2}$ up to 3 years old and $4 \mathrm{~mm}^{2}$ from 4 to 6 years old in this study.

The CSA value was confirmed immediately by repetitive measurement at the MedArm and the UlnProx from three children each in this study. The difference of the CSA at the MedArm between in the first and second measurements was $1 \mathrm{~mm}^{2}$ each, and there was no difference of the CSA at the UlnProx between in the first and second measurements.

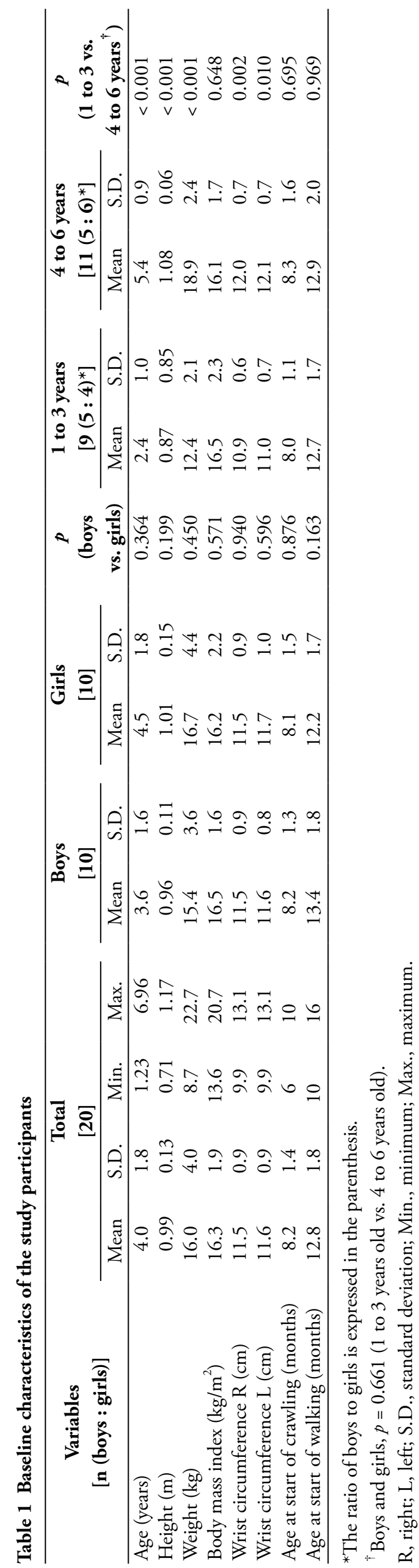


a CSA between boys and girls: MedArm

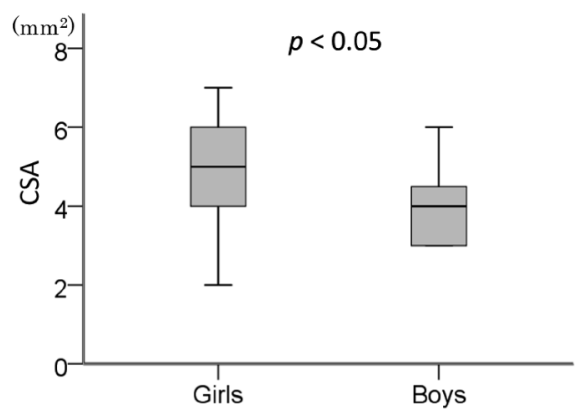

C CSA between evaluation sites

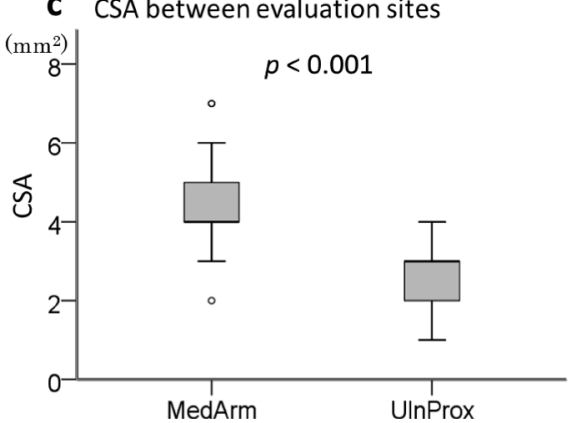

b CSA between boys and girls: UlnProx

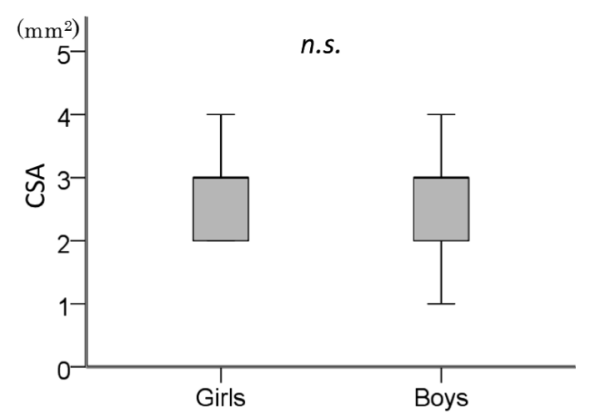

Fig. 2 The CSAs between boys and girls $(a, b)$ or the evaluation sites (c)

The CSA values are shown along the MedArm (a) and UlnProx (b). The CSA values are also shown for each evaluation site (c). The data in the box graph indicate the median, 25 th percentile and 75 th percentile.

n.s., not significant.
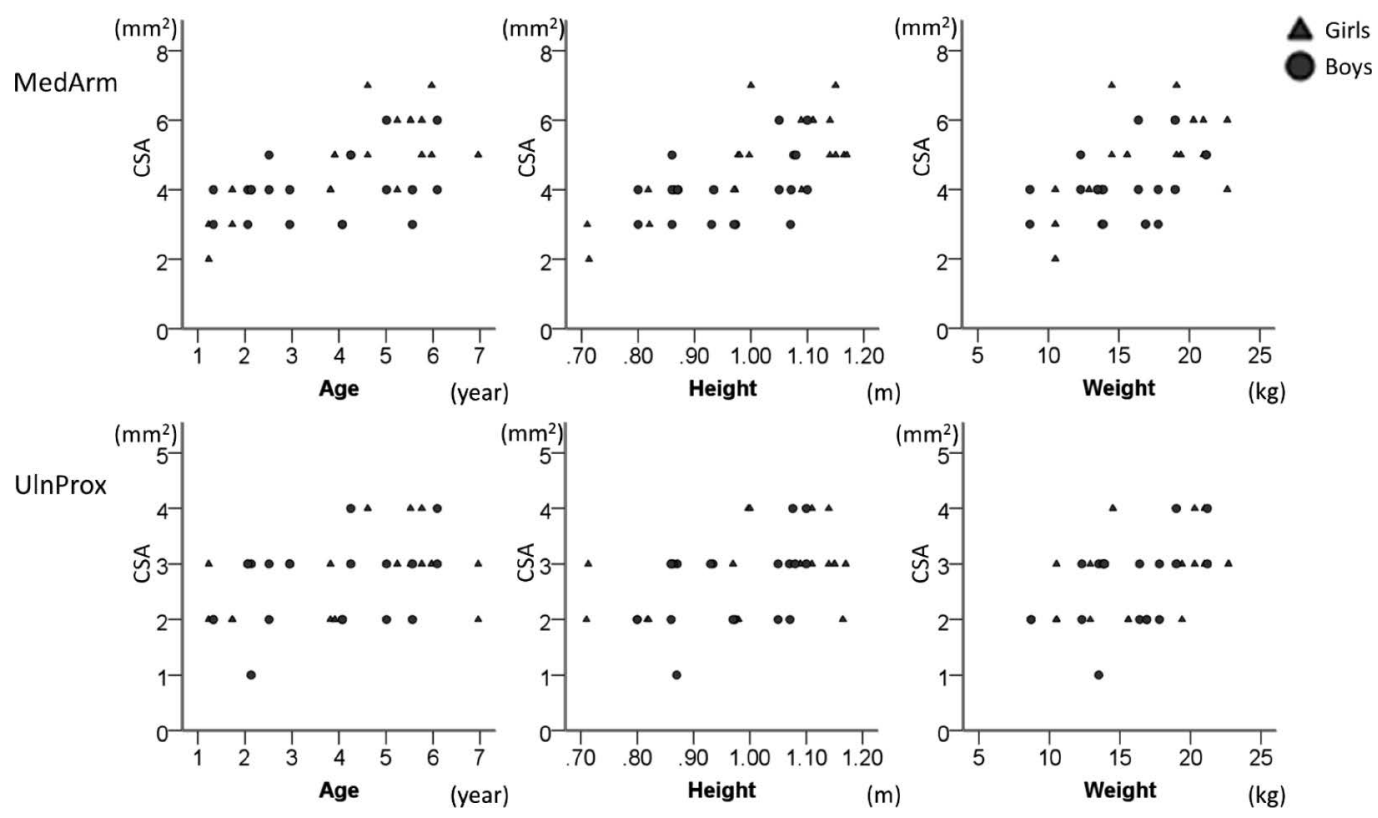

Fig.3 The CSAs along the peripheral nerves and parameters (age, height and weight)

\section{Discussion}

In this study, we could measure the CSA along the median and ulnar nerves in healthy Japanese children from 1 to 6 years old.

There are two studies of ultrasonographic evaluation for peripheral nerve CSA for children ${ }^{5,6}$, and the mean age was 9 and 11.4 years in the control group, respectively. The mean age of participants in our study, 4.0 years, was younger than the previous studies for children. Yiu et al. showed the difference of the CSA between CMT1A patients and controls ${ }^{5)}$. A marked increase in nerve CSA was present in children with CMT1A compared with controls. Therefore, it may be possible to differentiate normal nerve and pathological one in this precision by ultrasonography, even the minimal CSA value was $1 \mathrm{~mm}^{2}$. On the basis of our study, evaluation of the nerve CSA in children with demyelinating CMT should be started in Japan. 
Identification of the peripheral nerves was not technically difficult in children. The drawing of the cross-sectional image of the nerve at the UlnProx was nearly identical between adults and children. The median nerve at the MedArm in children was located relatively deeper from the skin surface compared to adults. Method of visualization for the nerve image and evaluation of the CSA should be referred to Sugimoto et al. ${ }^{4}$, and some experience is needed to detect the peripheral nerve and to evaluate CSA precisely using ultrasonography. The experience should be acquired from the expert for nerve ultrasonography at first, and the seminar should be held at regular intervals to reach the technique in the future.

In healthy adults, we reported that the existence of separate reference nerve sizes for gender might prove useful for simple assessments of patients ${ }^{4}$. On the basis of our results in this study, nerve size difference between boys and girls may exist at the MedArm, however, indicating that the mean age in girls was 1 year higher than in boys although the finding was not statistically different. CSA at the UlnProx was not different between adult males and females as previously reported $^{4)}$. Thus, the gender difference may not occur when nerve size was evaluated at the UlnProx. In children, we propose that the reference values of CSA at the MedArm and at the UlnProx stratified by age may serve as useful reference values for simple assessments of patients with peripheral neuropathies. The maximum CSA values should be carefully interpreted in practical that the maximum values are not the definite limit between normal and abnormal.

In adults, MedArm sites and UlnProx sites showed smaller errors with respect to intraobserver and interobserver reliability in ultrasonographic CSA measurement ${ }^{4}$. Therefore, we selected the two sites as measurement sites assumed that the intra- and interobserver variability were small even in children. Indeed, intraobserver variability seemed to be small even in children from this study. However, we did not verify the interobserver reliability of the CSA measurement to reduce the children's stress. Verification of intra- and interobserver variability will be needed for CSA measurement in the future research.

Our study had specific limitations. First, this study was performed on a relatively small population of participants. Thus, further data collection should be performed. Second, even if it was found that the participants had no family history and no gait disruption during the investigation, we could not confirm that the participants were definitely normal. Thus, there is a small probability that patients with inherited neuropathies were included in our study. However, no outlier of the CSA was observed in this study. Therefore, our data are applicable for practical use. Finally, we used a single diagnostic ultrasound imaging system in one research facility and one ultrasonographer. It is not known whether similar results would be obtained using different diagnostic ultrasound imaging systems at different research facilities with different ultrasonographers.

In conclusion, we could measure the nerve sizes in young children, and the participants in our study were younger than those of the previous studies. We suggested that reference CSA ranges stratified by age could be established to evaluate nerve enlargement in children with demyelinating CMT in screening tests. A comparison of CSAs along peripheral nerves between young children with demyelinating CMT and healthy young Japanese children should be addressed in future studies.

\section{Acknowledgments}

We would like to sincerely thank the nursing staff of the internal medicine outpatient division in Chugoku Rosai Hospital for their heartwarming support for the participants.

\section{Disclosure statement}

None of the authors has any conflict of interest to disclose.

\section{- References}

1) Sugimoto T, Ochi K, Hosomi N, et al.: Ultrasonographic nerve enlargement of the median and ulnar nerves and the cervical nerve roots in patients with demyelinating Charcot-Marie-Tooth disease: distinction from patients with chronic inflammatory demyelinating polyneuropathy. J Neurol 2013; 260: 2580-2587.

2) Zaidman CM, Harms MB, Pestronk A: Ultrasound of inherited vs. acquired demyelinating polyneuropathies. J Neurol 2013; 260: 3115-3121.

3) Sugimoto $\mathrm{T}$, Ochi $\mathrm{K}$, Hosomi N, et al.: Ultrasonographic diagnosis of inflammatory neuropathies. Brain Nerve 2014; 66: 223-228.

4) Sugimoto T, Ochi K, Hosomi N, et al.: Ultrasonographic reference sizes of the median and ulnar nerves and the cervical nerve roots in healthy Japanese adults. Ultrasound Med Biol 2013; 39: 1560-1570.

5) Yiu EM, Brockley CR, Lee KJ, et al.: Peripheral nerve ultrasound in pediatric Charcot-Marie-Tooth disease type 1A. Neurology 2015; 84: 569-574.

6) Zaidman CM, Al-Lozi M, Pestronk A: Peripheral nerve size in normals and patients with polyneuropathy: an ultrasound study. Muscle Nerve 2009; 40: 960-966.

7) Isojima $T$, Kato $N$, Ito $Y$, et al.: Growth standard charts for Japanese children with mean and standard deviation (SD) values based on the year 2000 national survey. Clin Pediatr Endocrinol 2016; 25: 71-76. 